\title{
Sofrimento Psíquico e Estratégias Defensivas Utilizadas por Desempregados: Contribuições da Psicodinâmica do Trabalho
}

\author{
Juliana Nunes de Oliveira ${ }^{1}$ \\ Ana Magnólia Mendes \\ Departamento de Psicologia Social e do Trabalho da Universidade de Brasilia, \\ Brasília, Distrito Federal, Brasil
}

\begin{abstract}
Resumo
Este estudo buscou investigar as principais vivências de sofrimento experienciadas por desempregados e as formas utilizadas para minimizá-las. O tema justifica-se pela necessidade de compreensão do desemprego advindo das mudanças sociais do sistema capitalista. Para subsidiar o estudo, foram feitas entrevistas semiestruturadas com oito pessoas que vivenciam a situação de não trabalho pelo período de cinco meses, em média. A análise dos dados foi realizada por meio da Análise de Conteúdo. Verificou-se que os participantes vivenciam mais sofrimento patogênico em detrimento do sofrimento criativo, sendo aquele relacionado à desvalorização, inutilidade e improdutividade. Para minimizar o sofrimento, os participantes buscam realizar o máximo de atividades possíveis, negando seu sofrimento. Os resultados encontrados podem servir de base para a elaboração de políticas públicas de apoio social e desenvolvimento para as pessoas que se encontram em situação de não trabalho. Sugere-se a realização de pesquisas futuras com a utilização de outras estratégias de coleta de dados.
\end{abstract}

Palavras-chave: Sofrimento psíquico, estratégias defensivas, desempregados.

\section{Psychic Suffering and Defensive Strategies Used by Unemployed: Contributions of the Psychodynamics of Work}

\begin{abstract}
This study aimed to investigate the main experiences of suffering experienced by the unemployed and the forms they use to minimize them. This theme is justified by the need to understand the social changes of unemployment arising from the capitalist system. To this, interviews were conducted with eight persons who experience the condition of not working for five months on average. Data analysis was performed by the Clinical Analysis of Work. It was found that participants experience more pathogenic suffering instead of creative suffering, and those is related to the devaluation, useless and unproductiveness. To minimize the pain, the participants seek to accomplish a lot of activities, denying their suffering. It is suggested the realization of other strategies of data collection.
\end{abstract}

Keywords: Psychic suffering, defensive strategies, unemployed.

Endereço para correspondência: CSB 08, Lotes 03/04, Apto 114, Taguatinga, DF, Brasil 72015-959. E-mail: juliananns@gmail.com

Agradecimento a Coordenação de Aperfeiçoamento de Pessoal de Nível Superior (CAPES), pela concessão de bolsa de estudo à Juliana Nunes de Oliveira. 


\section{Sufrimiento Psíquico y Estrategias Defensivas Utilizadas por los Desempleados: Contribuciones de la Psicodinámica del Trabajo}

\section{Resumen}

Este estudio propone investigar las principales experiencias de sufrimiento experimentado por el desempleados y las formas utilizadas para minimizarlos. El tema se justifica por la necesidad de comprensión del desempleo derivada de los cambios sociales del sistema capitalista. Para apoyar el estudio, las entrevistas semi-estructuradas se realizaron con ocho personas que experimentan la situación no trabajó durante cinco meses promedio. El análisis de datos se realizó mediante el análisis de contenido. Se encontró que los participantes experimentan más patógeno sufrimiento a costa del sufrimiento creativo, y las relacionadas con la devaluación, inutilidad e improductivo. Para reducir al mínimo el sufrimiento, los participantes tratan de realizar actividades máximos posibles, negando su sufrimiento. Estos resultados pueden servir de base para la elaboración de políticas públicas de apoyo social y el desarrollo de las personas que están en una situación de no trabajar. Se sugiere llevar a cabo más investigaciones con otras estrategias de recolección de datos.

Palabras clave: Sufrimiento psicológico, estrategias defensivas, desempleados.

Temas relacionados ao desemprego têm-se justificado pela necessidade de compreensão desse fenômeno devido às modificações advindas do sistema social vigente, que suscita o aumento do desemprego estrutural e sua repercussão na subjetividade dos sujeitos. O desemprego ressoa simbolicamente na subjetividade e possui consequências sociais e psicológicas para aqueles que o vivenciam (Cardoso, 2004). É importante observar que as taxas de desemprego no Brasil, atualmente, têm diminuído. No ano de 2012, houve uma redução de aproximadamente $4 \%$ na taxa do desemprego nas regiões metropolitanas do país, indicando um aumento no número de pessoas que trabalham no Brasil (Pessôa \& Barbosa, 2012).

Isto justifica a realização deste estudo, tendo em vista compreender o sofrimento daqueles que não possuem emprego em uma época em que o desemprego diminui. Este artigo investiga as principais vivências de sofrimento que são experienciadas por desempregados e as formas utilizadas para minimizá-las.

O trabalho exerce papel importante para a estruturação psíquica e para os processos de formação da identidade dos indivíduos. Além disso, o trabalho é visto como um aspecto central para a sociabilização contemporânea (Antunes, 2004; Dejours, 2006; Mendes, 2008). A ideologia do neoliberalismo acaba encobrindo e deslocando o trabalho da centralidade que ele ocupa na vida dos indivíduos para pontos mais periféricos, encobrindo processos de dominação e exploração advindas, principalmente, por meio do sistema capitalista. Tendo por base a ideia de separação do trabalhador e dos seus meios de produção, há, segundo uma concepção Marxista, o favorecimento da alienação deste trabalhador. No entanto, "o trabalho ocupa dimensão central nas formas de (des)sociabilidade contemporânea" (Antunes, 2004, p. 9) e deve-se pensar nele como a possibilidade que o sujeito tem para desenvolver a subjetividade por meio da relação entre sofrimento e real, de acordo com a teoria psicodinâmica do trabalho (Dejours, 2004).

A psicodinâmica do trabalho, disciplina clínica e teórica, busca descrever e compreender as relações entre trabalho e saúde mental, além de articular-se com a psicanálise e com a teoria social (Dejours, 2004). Análise das organizações do trabalho, das vivências de prazer e sofrimento e das formas de lidar com o sofrimento advindo do trabalho são temas de interesse dessa disciplina. Em consonância com essa teoria, buscou-se compreender neste estudo quais são as vivências de sofrimento experienciadas por desempregados, bem como as formas utilizadas para minimizá-lo. 


\section{O Desemprego e sua Decorrência nos Indivíduos}

O trabalho na pós-modernidade encontra-se em um contexto de alterações das mais diversas ordens. Termos como acumulação flexível, reestruturação produtiva, globalização, entre outros, incorporam, cada dia mais, o vocabulário de centenas de indivíduos que participam do sistema capitalista de consumo. A maneira de perceber e sentir o trabalho tem-se modificado consideravelmente e a estrutura econômica e política com a qual se convive atualmente exerce grande influência para essa modificação (Freitas, 2006). A diferenciação nos modos de fazer e sentir o trabalho, portanto, acabam por abarcar os mais diversos e complexos fenômenos, tais como a flexibilização da produção, as terceirizações, os contratos temporários, o subemprego e, finalmente, o desemprego (Abramides \& Cabral, 2003).

O fenômeno do desemprego não deve ser ignorado devido à importância que se atribui ao trabalho e à centralidade que este ocupa na vida dos indivíduos. Entende-se o desemprego como a falta ou ausência de trabalho, seguida pela busca desse, em que o sujeito possui disponibilidade para trabalhar. É, conforme a teoria keynesiana, uma condição involuntária de não trabalho (Galeazzi, 2011).

$\mathrm{O}$ desemprego atinge camadas que anteriormente eram vistas como mais protegidas, tais como profissionais escolarizados (Lima \& Gomes, 2010). Isso ocorre devido ao processo de reestruturação produtiva, a partir da década de 1970, o qual busca responder à crise sócio-político-econômica do capitalismo, inserindo alterações nas relações de produção ao incorporar a flexibilidade dos processos e do mercado de trabalho. A reestruturação produtiva, ainda, tem o objetivo implícito de recuperar a produção e a dominação da sociedade (Lancman \& Uchida, 2003) e traz implicações nas vivências dos trabalhadores. $\mathrm{O}$ trabalho para aqueles que se encontram em situação de desemprego significa a autonomia desejada, uma forma de se integrarem e de ascenderem socialmente por meio da carreira. Quando lhes falta o trabalho, os seus interesses em aprenderem coisas novas e se en- volverem na vida social torna-se precário, e se veem envoltos em um vazio que é caracterizado pelo tédio. Isso mostra que o desemprego ressoa simbolicamente na subjetividade dos indivíduos (Padilha, 2000).

Além disso, atenta-se ao trabalho não somente como uma forma de acumulação de capital, mas também, um lugar social, um espaço onde o indivíduo tem a possibilidade de reconhecer-se como um sujeito que produz. No entanto, quando o indivíduo não tem essa possibilidade de produção, ele não se identifica dessa forma, vendo-se obrigado a conseguir qualquer emprego que the couber, caracterizando-se, assim, o fenômeno do subemprego (Wickert, 1999).

Observa-se que o desemprego associa-se às experiências de sofrimento como tristeza e exclusão social (Tumolo \& Tumolo, 2004). Além disso, verifica-se que ele possui consequências sociais e psicológicas para os que se encontram nela. Tais consequências estão relacionadas à fragilização do seu papel como produtor social, em que esses indivíduos sentem-se excluídos e, consequentemente, não participantes da estrutura social (Cardoso, 2004).

O sujeito que se encontra em uma situação de não trabalho pode vivenciar uma (des)socialização progressiva, ou seja, perder o seu lugar social no mundo de forma gradual, o que pode causar um forte sofrimento psíquico (Dejours, 2006). Assim, o trabalho é uma oportunidade de transformação desse sofrimento, no qual o indivíduo que trabalha pode, em algumas situações, preservar melhor sua saúde do que aquele que não o faz (Dejours, 2006). O estudo do sofrimento e das estratégias defensivas utilizadas para minimizar este sofrimento é importante também para um público que se encontra em situação de desemprego.

\section{Sofrimento e Estratégias Defensivas Relacionadas ao Trabalho}

O sofrimento é vivenciado nos mais diversos contextos, porém no trabalho o sujeito tem a oportunidade de transformar esse sofrimento em criatividade, a serviço da sua saúde. Também é no trabalho que esse sofrimento pode vir a ser 
um sofrimento patogênico, fragilizando a saúde do trabalhador (Dejours, Abdoucheli, \& Jayet, 1994).

Dessa forma, Dejours (1996) faz uma diferenciação entre sofrimento criativo e sofrimento patogênico, em que o primeiro constitui-se da elaboração de estratégias criativas que, em geral, favorecem à saúde do sujeito e à produção. Com isso, o autor argumenta que não se deve negar o sofrimento do sujeito, pois é inevitável, mas o sofrimento criativo possibilita a transformação desse estado em criatividade, contribuindo para a resistência do sujeito à desestabilização. Já aquele considerado patogênico caracteriza o sofrimento que gera alguma solução desfavorável à saúde, no sentido de que o sujeito pode estar em vias de adoecimento ou já estar adoecido. Pode-se afirmar que esse sofrimento ocorre quando o trabalhador esgota seus recursos defensivos, levando-o à descompensação e à doença. $\mathrm{O}$ sofrimento, portanto, pode tanto assumir um papel de mobilizador da saúde do sujeito, uma vez que o auxilia a pensar de forma crítica o seu trabalho, quanto pode ser um instrumento que é utilizado para o aumento da produtividade e aliena o sujeito (Mendes, 2007).

O trabalhador lida com esse sofrimento utilizando-se de alguns recursos chamados de estratégias defensivas, que podem ser tanto individuais quanto coletivas. As estratégias individuais de defesa são caracterizadas pelos mecanismos de defesa operantes, os quais estão interiorizados e operam mesmo sem a presença do outro. Essas estratégias possuem importante papel para a adaptação ao sofrimento, porém são de natureza individual, não atuando sobre a violência social (Dejours, 2006). Já as estratégias coletivas de defesa necessitam de um consenso do grupo e dependem de condições externas ao sujeito (Dejours et al., 1994). Essas estratégias são construídas por um grupo de trabalhadores para resistir aos efeitos desestabilizadores e para lidar com as contradições advindas do trabalho. Elas contribuem para a coesão do coletivo de trabalho (Dejours, 2006). As defesas podem ser pensadas tanto como fatores de alienação por não atuarem na modificação da realidade que faz sofrer e, consequentemente, possíveis causado- res de adoecimento, como podem também ser pensadas como aquelas que desempenham um papel considerável para a manutenção da saúde, por minimizarem a percepção que o trabalhador tem do sofrimento (Mendes, 2007).

Uma divisão ainda mais específica sobre as estratégias defensivas é feita por Dejours (2004), em que ele as classifica em defesas (a) de proteção, (b) de adaptação e (c) de exploração. As defesas de proteção são formas de pensar e agir de modo a proteger-se do sofrimento advindo do trabalho e fazem com que esse sofrimento seja racionalizado ou evitado. Com isso, essas defesas auxiliam o trabalhador a tornar-se alheio às causas do sofrimento, tendo por consequências a intensificação deste ou o adoecimento. Já as defesas de adaptação e de exploração estão relacionadas à submissão aos desejos de produção da organização, em que o trabalhador se sujeita a comportamentos inconscientes que atendam à produção e ao funcionamento, por vezes, perverso da organização do trabalho (Mendes, 2007). Diversas pesquisas utilizando o arcabouço teórico e metodológico da psicodinâmica do trabalho foram realizadas no Brasil para estudar as estratégias defensivas utilizadas pelos trabalhadores diante de uma organização do trabalho, com grande variedade de categorias profissionais (Almeida, 2002; Mendes, Costa, \& Barros, 2003; Veronese, 2000). Observa-se, no entanto, que pesquisas publicadas utilizando essa mesma disciplina teórica, com enfoque em pessoas que experimentam situações de não trabalho, aparecem em menor número. Uma dessas pesquisas é a de Lima e Gomes (2010), a qual analisa como o desemprego afeta a subjetividade de indivíduos recém-formados. O objetivo do estudo desses autores foi analisar como o desemprego ressoa na subjetividade de recém-formados. Com isso, encontrou-se que a visão de trabalho para os participantes da pesquisa está ligada, principalmente, ao valor econômico e financeiro e à sobrevivência, bem como a uma fonte de prazer. Também apresentou o trabalho enquanto um sistema de referência social, no qual o indivíduo percebe a sua utilidade para a sociedade.

Dessa forma, cabe analisar as estratégias de enfrentamento do sofrimento que são utili- 
zadas por aqueles que não estão submetidos a uma organização do trabalho operando sobre sua subjetividade. Toma-se por base o trabalho como estruturante psíquico; todavia, aqueles que se encontram em situação de desemprego e que vivenciam o sofrimento relacionado ao não trabalho também se utilizam de estratégias para minimizar seu sofrimento, constituindo-se, igualmente, num importante objeto a ser investigado.

\section{Método}

\section{Participantes}

Participaram deste estudo oito pessoas, sendo cinco homens e três mulheres. Um participante possui ensino superior completo, dois estão cursando as fases finais do ensino superior (sexto e sétimo semestres de cursos compostos por oito semestres) e cinco possuem ensino médio completo.

Todos os participantes são residentes em Brasília, Distrito Federal, local onde foi realizada esta pesquisa. A média de tempo desses participantes em situação de não trabalho foi de aproximadamente cinco meses $(D P=2,17)$. A idade dos participantes variou entre 23 e 30 anos de idade, sendo a média de idade de 26 anos $(D P=1,89)$.

\section{Instrumento}

A fim de favorecer a expressão livre dos participantes da pesquisa, utilizou-se um roteiro de entrevista semiestruturado com questões abertas. O roteiro foi constituído por três perguntas-chave, cujo papel foi orientar a entrevista realizada. Ele foi baseado no referencial teórico da Psicodinâmica do Trabalho (Dejours, 1996, 2004; Dejours et al., 1994), adaptando um roteiro de entrevista utilizado em estudos realizados por Mendes (2007). A Psicodinâmica do Trabalho busca compreender o contexto de trabalho no qual o sujeito está inserido, como é a organização do trabalho dos indivíduos, quais são as condições de trabalho e as relações socioprofissionais estabelecidas em determinada organização. Além disso, também objetiva analisar os sentimentos relacionados ao trabalho, os modos de enfrentar o trabalho e as patologias sociais que podem estar relacionadas ao trabalho. Em consonância com esta teoria, foram utilizadas as seguintes perguntas:

"O que você pensa/sente a respeito da sua situação de não trabalho?". Os objetivos da pergunta foram: explorar as vivências de sofrimento, explorar os sentimentos do entrevistado com relação à sua situação de não trabalho, buscar exemplificações e características de situações que tem vivenciado a respeito da sua situação de não trabalho.

"O que você faz para lidar com as dificuldades ocasionadas pela situação de não trabalho?". Os objetivos foram identificar as soluções encontradas para lidar com as dificuldades de não trabalho, tanto no plano material quanto no contexto emocional, estratégias de mediação para enfrentar/superar/transformar o sofrimento.

"Você acredita que a situação de não trabalho está afetando a sua saúde? De que maneira?". Os objetivos, aqui, foram investigar patologias decorrentes da situação de não trabalho e verificar saúde e riscos de adoecimento.

\section{Procedimentos de Coleta de Dados}

Para a realização deste estudo foi feita uma parceria com uma consultoria de recursos humanos do Distrito Federal para a execução da seleção dos participantes. Foi afixado um anúncio a respeito da pesquisa na recepção da consultoria e aqueles que se interessaram, preencheram um questionário e colocaram-no em um envelope. $\mathrm{O}$ anúncio ficou em exposição pelo período de uma semana. Após esse período, foi realizado contato, prestou-se esclarecimento sobre a pesquisa e foram agendadas as entrevistas com os interessados.

As entrevistas foram realizadas por uma pesquisadora e, inicialmente, foi informado ao entrevistado sobre o que se tratava a pesquisa, sobre a possibilidade de desistir de participar a qualquer momento e ainda sobre a possibilidade de receber os resultados, caso houvesse interesse. Posteriormente, solicitou-se que o entrevistado assinasse o Termo de Consentimento Livre e Esclarecido (TCLE). 
Foram realizadas entrevistas individuais, gravadas com autorização de todos os participantes, cuja duração foi de, aproximadamente, uma hora cada, seguindo o roteiro de entrevista e acrescentando algumas perguntas, a fim de se aprofundar nas questões trazidas pelo entrevistado.

Os dados desta pesquisa foram coletados entre fevereiro e agosto de 2013, em período considerado como, tradicionalmente, de oferta regular de empregos em Brasília, Distrito Federal. Sendo assim, não está relacionado ao período de boom de empregos temporários, acarretados, principalmente, pelas festividades de final de ano.

\section{Procedimentos de Análise de Dados}

A análise dos dados foi feita com base na Análise de Conteúdo proposta por Bardin (1977, p. 42), que a define como

um conjunto de técnicas de análise das comunicações visando obter, por procedimentos sistemáticos e objectivos de descrição de conteúdo das mensagens, indicadores (quantitativos ou não) que permitam a inferência de conhecimento relativos às condições de produção/recepção (variáveis inferidas) destas mensagens.

Como técnica, foi utilizada a análise categorial temática, visando descrever categorias significativas do discurso dos sujeitos. Esta técnica é realizada por meio do desmembramento do texto em categorias que são, de acordo com Bardin (1977, p. 199) "reagrupamentos analógicos" Dessa forma, foram realizadas leituras flutuantes do material transcrito das entrevistas, identifica- ção dos temas e agrupamento em categorias pela semelhança dos conteúdos. As entrevistas foram categorizadas separadamente e, posteriormente, foram feitas categorias-síntese, que serão apresentadas na sessão de resultados.

Salienta-se que foi realizada análise indutiva do material explorado. Além disso, buscou-se atender aos critérios de exaustividade, representatividade, homogeneidade, pertinência e exclusividade, além de contar com o auxilio da análise de dois juízes. Esses juízes auxiliaram em todas as etapas da análise, principalmente na obtenção dos critérios descritos acima e ao debater a respeito das categorias encontradas.

Considerando-se os aspectos subjetivos das estratégias de mediação do sofrimento utilizadas por desempregados, acredita-se que a técnica da Análise de Conteúdo seja adequada, uma vez que esta pressupõe escuta e livre expressão do sujeito. Além disso, essa técnica auxilia a ter uma visão mais clara dos aspectos mais recorrentes na fala e dos participantes.

\section{Resultados}

De acordo com os objetivos desta pesquisa e em consonância com a natureza dos dados coletados, as informações serão apresentadas conforme as categorias encontradas nos relatos dos participantes. Nesses relatos, foram encontradas três categorias denominadas: Sentimentos relacionados à situação de não trabalho; Estratégias para lidar com o desemprego; Danos físicos e psicossociais ocasionados pela situação de não trabalho. As categorias serão apresentadas a seguir nas Tabelas 1, 2 e 3. 
Tabela 1

\author{
Categoria-Síntese "Sentimentos Relacionados à \\ Situação de Não Trabalho"
}

\begin{tabular}{|c|c|}
\hline \multicolumn{2}{|r|}{ Definição } \\
\hline \multicolumn{2}{|r|}{$\begin{array}{l}\text { Diversos sentimentos são vivenciados por aqueles } \\
\text { que se encontram em situação de desemprego como } \\
\text { sentirem-se improdutivos e inúteis, bem como insegu- } \\
\text { ros com relação as suas situações de caráter instável. } \\
\text { Também sentem angústia e ansiedade por vivenciarem } \\
\text { sensação de perda de tempo. }\end{array}$} \\
\hline \multicolumn{2}{|r|}{ Temas } \\
\hline & Ansiedade; \\
\hline- & Improdutividade por não realizar uma atividade; \\
\hline & Desvalorização; \\
\hline & Inutilidade; \\
\hline & Insegurança. \\
\hline
\end{tabular}

Exemplos de verbalizações

"Ah... É uma situação complicada, porque você se sente improdutivo, sem estar exercendo uma atividade."

"É muito ruim, porque eu me sinto desvalorizado, porque leva um pouco de tempo pra se recolocar no mercado e ganhar confiança de novo."

"Eu fico muito ansioso, porque eu sinto falta daquele momento, daquele espaço."

"Eu me sinto muito improdutivo. Eu me sinto... inútil."

"É uma ansiedade assim, como eu falei, você quer preencher aquele espaço. Você quer ocupar aquele tempo com alguma coisa."

Esta categoria evidencia os principais sentimentos experienciados por este grupo de pessoas que se encontram em situação de não trabalho. Pela situação em que se encontram, sentem-se desvalorizados, improdutivos, inseguros, evidenciando uma situação desconfortável que gera certo sofrimento nesses sujeitos. Os entrevistados relatam que se sentem inseguros quanto a sua situação, uma vez que não sabem por quanto tempo esta perdurará. Este sentimento de insegurança está atrelado tanto a atributos materiais, como à falta de dinheiro para a subsistência, além dos atributos psicológicos, como o medo da falta de atividades a serem realizadas.
Tabela 2

Categoria-Síntese "Estratégias para Lidar com o Desemprego"

\section{Definição}

Há relatos de busca de atividades diversas, a fim de minimizar o sofrimento ocasionado pela situação de não trabalho. Há tentativas de pensar em atividades relacionadas à sua área de trabalho, mesmo não trabalhando. Com relação às condições financeiras, buscam adaptar-se com o que consideram básico, sem realizar compras excessivas ou supérfluas e tentando sobreviver com o possível. Também buscam constantemente por oportunidades de trabalho, mesmo que estas não estejam relacionadas à sua área profissional.

\begin{tabular}{ll}
\hline \multicolumn{1}{c}{ Temas } \\
\hline - & Realização de atividades diversas; \\
- $\quad$ Pensar em atividades relacionadas à área de \\
atuação; \\
- $\quad$ Utilização controlada dos recursos financeiros; \\
\hline
\end{tabular}

Exemplos de verbalizações

“. . . às vezes você tem muitas ideias, mas 'dai' você não 'tá' trabalhando. Você pode colocar essas ideias em algum outro ponto, mas você gostaria de 'tá' colocando no seu trabalho, ali no dia a dia".

"Na maioria das vezes, busco entretenimento: televisão, assistir um filme, alguma outra coisa, vai na internet, busca algumas leitura".

"Enfim, tentar adaptar com o básico, com o que eu já tinha antes de ter saído do emprego".

"Tô procurando encontrar uma forma de voltar, mesmo que não seja especificamente pra área que eu já atuo, mas, enfim, buscar novamente me recolocar no mercado".

Observam-se, nesta categoria, os esforços empreendidos por estes sujeitos para lidarem com a situação de desemprego pela qual estão passando. Realizar as mais diversas atividades, buscarem se recolocar no mercado de trabalho, manterem-se com o básico para sua subsistência são algumas estratégias que utilizam para lidar com esta situação. 
Tabela 3

Categoria-Síntese "Danos Físicos e Psicossociais Ocasionados pela Situação de Não Trabalho"

\section{Definição}

Diversos danos físicos e psicossociais são relatados pelos participantes e estão relacionados à possibilidade de estarem realizando alguma atividade trabalho, porém não a realizam. A ausência de rotina é apresentada como um fator que auxilia na presença de danos que afetam a saúde.

\begin{tabular}{ll}
\hline \multicolumn{1}{c}{ Temas } \\
\hline$-\quad$ Dor de cabeça; \\
$-\quad$ Insônia; \\
$-\quad$ Estresse; \\
$-\quad$ Ansiedade; \\
- $\quad$ Problemas com alimentação. \\
\hline
\end{tabular}

Exemplos de verbalizações

"Eu tenho insônia, às vezes dor de cabeça, às vezes um pouco de fadiga por não conseguir dormir direito. Então, uma indisposição por não estar fazendo nada. Não ter uma, 'né', enfim, não conseguir ocupar com uma atividade fisica".

"E o fato de eu não estar trabalhando me deixa mais estressado, mais chateado, do que eu estar trabalhando, porque, enfim... Eu queria estar fazendo alguma coisa".

"Eu poderia estar trabalhando, exercendo alguma função naquele momento, mas não estou. E aí isso me deixa estressado e ansioso."

“Às vezes eu fico ansioso e fico tentando preencher isso com alimentação. Tô ansioso, ao invés de fazer alguma coisa, eu fico apreensivo e vou comer."

“. . . então você fica um pouco mais lento, mais preguiçoso, acaba acordando um pouco mais tarde, dormindo mais tarde, ou seja, não tem uma rotina como tinha antes, né?"

Evidenciam-se, nesta categoria, os principais danos físicos e psicossociais relacionados à situação de não trabalho para estes entrevistados. Eles relatam sentir dores de cabeça, insônia, fadiga, estresse, ansiedade, entre outros danos físicos e psicossociais ocasionados pela sua situação.

\section{Discussão}

Os participantes, mesmo que estejam vivenciando uma situação de desemprego, experienciam o sofrimento relacionado à situação de não trabalho, logo relacionado ao trabalho e, consequentemente, utilizam-se de estratégias de enfrentamento para amenizar o sofrimento e promover sua saúde mental. As estratégias defensivas "levam à modificação, transformação e, em geral, à eufemização da percepção que os trabalhadores têm da realidade que os faz sofrer" (Dejours et al., 1994, p. 128). Logo, estas são utilizadas pelo trabalhador como uma possibilidade de minimizar o seu sofrimento e estas estratégias defensivas são utilizadas pelos sujeitos em estudo.

Verifica-se, neste caso, a predominância de sofrimento patogênico, em detrimento do sofrimento criativo. $\mathrm{O}$ sofrimento criativo resulta na criação de soluções originais que visam à promoção da saúde (Dejours, 1996), contudo, neste caso, observa-se que os entrevistados vivenciam mais o sofrimento patogênico. Isso pode ser observado pela frequência em que o sofrimento patogênico aparece no discurso dos sujeitos.

Ainda se observa que, mesmo em menor frequência, há uma busca por soluções criativas para a situação vivenciada e esta busca está bastante relacionada ao trabalho. Esse foco no mundo do trabalho dado pelos participantes pode ser devido às perguntas da pesquisa, as quais são relacionadas ao trabalho, porém, também podem evidenciar a centralidade do trabalho na vida desse sujeito. Essas evidências corroboram os argumentos de Antunes (2004, p. 9), o qual relata que "o trabalho ocupa dimensão central nas formas de (des)sociabilidade contemporânea". Heloani e Lancman (2004) também corroboram esta visão ao argumentarem que o foco de análise deve ser no trabalhar, visto além da venda da força de trabalho. O trabalho deve ser visto também como um fator de pertinência a grupos sociais, auxiliando na constituição da identidade do sujeito.

O sofrimento dos sujeitos está mais relacionado à desvalorização, inutilidade e improdutividade, termos aparentemente referentes às 
características contrárias ao que é exigido pelo sistema capitalista de consumo, tais como velocidade e produtivismo. O modo de produção capitalista, ao consolidar-se, determina hierarquias de dominação e subordinação, fundamentando-se na alienação do trabalhador, pois há a separação do trabalhador e dos seus meios de produção. Além disso, há a dependência dos trabalhadores ao capital para a sua sobrevivência, personificando os trabalhadores como o próprio trabalho, o que favorece a alienação (Antunes, 2000).

Com o advento do capitalismo "as relações sociais passam a ser submetidas ao imperativo da lógica de acumulação de capital. Assim, a categoria trabalho passa a ter uma centralidade na vida social e na constituição da identidade do sujeito" (Freitas, 2006, p. 28). Isto posto, observa-se que o sofrimento dos sujeitos está relacionado, principalmente, a características que vão na contramão do que é exigido pelo sistema capitalista, evidenciando como o sistema de consumo pode ressoar na subjetividade do sujeito, afetando, consequentemente, sua saúde.

Ao abordarem sobre a insegurança da situação que vivenciam e sobre a impossibilidade de sociabilização, observa-se que esses dados corroboram as colocações de Heloani e Lancman (2004), os quais afirmam que o trabalho pode ser considerado a matriz da integração social, ou seja, pode ser considerado um fator importante para a sociabilização dos indivíduos.

Diante do sofrimento vivenciado pelo sujeito, no entanto, não se deve considerá-lo um mal em si, mas uma possibilidade de impulso para a ação, para o encontro de estratégias criativas de modificação da realidade que o faz sofrer. Assim, é importante analisar que "estratégias defensivas surgem com o sofrimento e, por meio delas, os trabalhadores conseguem minimizar a percepção que têm das pressões organizacionais. De vítimas passivas, os trabalhadores passam a agentes ativos de um desafio" (Scolari, Costa, \& Mazzili, 2009, p. 557).

Ao se observar sobre patologia, nota-se que esta não foi encontrada nas falas dos participantes. Isso pode ser um indício de que as defesas têm agido sobre a subjetividade do sujeito, pre- servando a sua saúde, muito embora possam ser consideradas também como uma forma de alienação.

Ao se observarem mais especificamente as defesas que são utilizadas pelos participantes, nota-se uma busca por ocupar-se com o máximo de atividades possíveis, em uma tentativa de manter-se produtivo, afim de negar seu sofrimento. Dessa forma, é possível verificar que essas atividades em excesso podem proteger o sujeito de sua própria angústia gerada pela ausência de emprego, ou também podem servir como uma forma de negação de sua situação.

Observa-se que os participantes buscam formas de estarem inseridos no mercado de trabalho, mesmo que não seja na área de atuação a qual possuem o maior período de experiência. Essa busca por trabalho é uma forma de prestarem contas a si mesmo e a todos os que os acompanham, numa tentativa de mostrar que se encontram em movimento e em busca, sendo assim, não acusados de serem acomodados.

Nota-se que as estratégias mais utilizadas pelos entrevistados são estratégias individuais de enfrentamento do sofrimento. Isso pode ser devido às características do desemprego, as quais estão relacionadas à exclusão social daquele que não trabalha. Neste sentido, os próprios participantes não veem possibilidades de se utilizarem de estratégias coletivas, mesmo porque esses não possuem um coletivo no qual podem construir estratégias de enfrentamento do sofrimento vivenciado.

De forma geral, observou-se nos entrevistados que as defesas as quais fazem utilização estão mais relacionadas às defesas de adaptação, no qual o sujeito nega seu sofrimento, adaptando-se a ele. Essa negação caracteriza-se pela interiorização e naturalização das vivências de sofrimento e por comportamentos de isolamento, desconfiança e individualismo (Mendes, 2007).

Além disso, cabe salientar, que não houve a presença de características ligadas à exclusão social. Nenhum dos participantes do estudo relatou sentir-se excluído socialmente devido a sua condição de não trabalho. O desemprego pode estar associado às experiências de exclusão social (Tumolo \& Tumolo, 2004) e pode ter consequ- 
ências sociais e psicológicas para esses sujeitos (Cardoso, 2004). No entanto, o que se observa neste estudo é que o desemprego têm consequências psicológicas para os sujeitos, porém, ao serem observadas as consequências sociais, essas não puderam ser verificadas nesses participantes. Essa característica pode estar associada à idade jovem dos participantes do estudo (média de 26 anos), bem como à média de tempo que se encontram desempregados (cinco meses). Por tratar-se de jovens trabalhadores que se encontram desempregados, estes podem contar com o auxílio de pessoas próximas, como seus familiares ou amigos. Além disso, a média de tempo em situação de desemprego considerada relativamente baixa pode ser um fator que influencia na falta de consequências sociais do desemprego desses indivíduos.

\section{Considerações Finais}

O estudo permitiu conhecer as vivências de sofrimento de desempregados à luz da teoria da Psicodinâmica do Trabalho, bem como as formas utilizadas para minimizar o sofrimento. Compreender o sofrimento vivenciado por pessoas desempregadas e as estratégias utilizadas por essas pessoas para minimizarem o seu sofrimento é um conhecimento válido.

No entanto, o estudo possui algumas limitações que devem ser observadas. Uma limitação é a utilização de apenas uma técnica de coleta de dados. Por se utilizar da entrevista como estratégia de coleta de dados, a desejabilidade social pode ter feito parte de algumas entrevistas. Outra limitação deste estudo é a realização em apenas uma cidade do Distrito Federal, o que reduz a expansão desse conhecimento para além da cidade pesquisada, bem como a utilização de um número reduzido de participantes. Além disso, compete-se analisar o local no qual os participantes foram selecionados. Por tratar-se de uma consultoria, os participantes selecionados podem ter sidos atraídos para a pesquisa com o pensamento de que esta seria uma das etapas de algum processo seletivo para obtenção de emprego.

Sugere-se que pesquisas futuras sejam realizadas utilizando outras estratégias de coleta de dados, além da entrevista, para que sejam minimizados os vieses de autorrelato. Também se sugere o aumento do número de participantes, a fim de que a pesquisa tenha mais confiabilidade e fidedignidade e, se possível, que sejam feitas pesquisas a nível nacional com um número de participantes representativo da população brasileira.

Mesmo com as limitações deste estudo, este pode ser entendido como base para a realização de pesquisas futuras, bem como se pode pensar na construção de políticas públicas com ações voltadas aos desempregados, como grupos de apoio ou de desenvolvimento. Acredita-se que compartilhar o sofrimento com demais pessoas que passam pela mesma vivência seja uma ação importante para criação e fortalecimento de laços e redes em que os sujeitos possam ter apoio e suporte social.

\section{Referências}

Abramides, M. B. C., \& Cabral, M. S. R. (2003). Regime de acumulação flexível e saúde do trabalhador. São Paulo em Perspectiva, 17(1), 3-10.

Almeida, N. D. V. (2002). Contemporaneidade x trânsito: Reflexão psicossocial do trabalho dos motoristas de coletivo urbano. Psicologia, Ciência e Profissão, 22(3), 62-69.

Antunes, R. (2000). Os sentidos do trabalho: Ensaio sobre a afirmação e a negação do trabalho. São Paulo, SP: Boitempo.

Antunes, R. (2004). O avesso do trabalho. São Paulo, SP: Expressão Popular.

Bardin, L. (1977). Análise de conteúdo. Lisboa, Portugal: Edições 70.

Cardoso, G. R. (2004). "Estou desempregado, não desesperado": A vivência do desemprego para trabalhadores desempregados frequentadores do SINE de Florianópolis (Dissertação de mestrado, Instituto de Psicologia, Universidade Federal de Santa Catarina, Florianópolis, SC, Brasil).

Dejours, C. (1996) Uma nova visão do sofrimento humano nas organizações. In J Chanlat, $O$ indivíduo na organização (pp. 149-173). São Paulo, SP: Atlas.

Dejours, C. (2004). Addendum: Da psicopatologia à psicodinâmica do trabalho. In S. Lancman \& L. 
I. Snelwar, Christophe Dejours: Da psicopatologia à psicodinâmica do trabalho (pp. 47-104). Rio de Janeiro, RJ: Fundação Oswaldo Cruz.

Dejours, C. (2006). A banalização da injustiça social. Rio de Janeiro, RJ: Fundação Getúlio Vargas.

Dejours, C., Abdoucheli, E., \& Jayet. C. (1994). Psicodinâmica do trabalho: Contribuições da escola Dejouriana à análise da relação prazer, sofrimento e trabalho. São Paulo, SP: Atlas.

Freitas, L. G. (2006). Saúde e processo de adoecimento no trabalho dos professores em ambiente virtual (Tese de doutorado, Instituto de Psicologia, Universidade de Brasília, DF, Brasil).

Galeazzi, I. (2011). Desemprego. In A. D. Cattani \& L. Holzmann (Eds.), Dicionário de trabalho e tecnologia. Porto Alegre, RS: Zouk.

Heloani, R., \& Lancman, S. (2004). Psicodinâmica do trabalho: O método clínico de intervenção e investigação. Revista Produção (São Paulo), 14(3).

Lancman, S., \& Uchida, S. (2003). Trabalho, e subjetividade: O olhar da psicodinâmica do trabalho. Cadernos de Psicologia Social do Trabalho, 6, 79-90.

Lima, A. V. Q., \& Gomes, M. W. F. (2010). "Estou formado(a), e agora?": Uma análise sobre o sofrimento psíquico de desempregados recém-formados em instituições de nível superior em São Luís-MA. Cadernos de Pesquisa (São Luis), 17(3), 37-46.

Mendes, A. M. (2007). Da psicodinâmica à psicopatologia do trabalho. In A M. Mendes (Ed.), Psicodinâmica do trabalho: Teoria, métodos e pesquisa. São Paulo, SP: Casa do Psicólogo.
Mendes, A. M. (2008). Prazer, reconhecimento e transformação do sofrimento no trabalho. In A. M. Mendes (Ed.), Trabalho e saúde: O sujeito entre emancipação e servidão. Curitiba, PR: Juruá.

Mendes, A. M., Costa, V. P., \& Barros, P. C. R. (2003). Estratégias de enfrentamento do sofrimento psíquico no trabalho bancário. Estudos e Pesquisas em Psicologia (Rio de Janeiro), 3(1).

Padilha, V. (2000). Tempo livre e capitalismo: Um par imperfeito. Campinas, SP: Alínea.

Pessôa, S. A., \& Barbosa, F. H., Filho. (2012). Uma análise da redução da taxa de desemprego. REAP, 3 .

Scolari, C., Costa, S. G., \& Mazzilli, C. (2009). Prazer e sofrimento entre os trabalhadores de Call Center. Psicologia USP, 20(4), 555-576.

Tumolo, L. M., \& Tumolo, P. S. (2004). A vivência do desempregado: Um estudo crítico do significado do desemprego no capitalismo. Espaço Acadêmico, 43, 1-13.

Veronese, M. V. (2000). A noite escura e bela: Um estudo sobre o trabalho noturno. Psicologia \& Sociedade, 12(1), 174-193.

Wickert, L. F. (1999). O adoecer psíquico do desempregado. Psicologia, Ciência e Profissão, 19(1), 66-75.

Recebido: 02/09/2013

$1^{a}$ revisão: $29 / 12 / 2013$

Aceite final: 17/01/2014 